\title{
Gauging the Level of Reflective Teaching Practices among Science Teachers
}

\author{
Ali Khaled Bawaneh \\ Dr., Corresponding author, Deanship of Academic Development, Imam Abdulrahman \\ Bin Faisal University, Saudi Arabia, akbawaneh@iau.edu.sa
}

\section{Ahmed Boudjema Hamida Moumene}

Prof., Deanship of Preparatory Year and Supporting Studies, Imam Abdulrahman Bin Faisal University, Saudi Arabia, abmoumene@iau.edu.sa

\section{Osamah Aldalalah}

Assoc. Prof., in Educational Technology, Taibah University, Saudi Arabia, odalalah@taibahu.edu.sa

The study aimed at detecting the level of reflective teaching practices used by science teachers in classrooms. It sought to examine the potential alteration of these practices in terms of some variables, namely gender, qualification, experience, and load. The population consisted of all science teachers of physics, chemistry, and biology in the Bani Kenana educational directorate, Jordan. A representative sample of 256 teachers participated in this research work. The study adopted a twenty-seven-item questionnaire for data collection, used the SPSS program for data analysis, and provided statistical measures. The results indicated that the degree of employment of reflective teaching practices by science teachers was somewhat low but also varied depending on the kind of questions raised. They also demonstrated that there were statistically significant differences at the level of $(\alpha=0.05)$ in the degree of employment of reflective teaching practices due to teachers' gender. However, the results also showed that there were no statistically significant differences for the variables of qualification, experience and load. Henceforth, the study recommended the urgent need of providing teachers with professional development programs for instructing them and raising their awareness of the utility of reflective teaching practices. The study also recommended the supplementation of all disciplinary teacher guides with efficient mechanisms for furthering reflective teaching practices.

Keywords: teaching, learning, reflective teaching practices, science teaching, science teachers

Citation: Bawaneh, A. K., Moumene, A. B. H., \& Aldalalah, O. (2020). Gauging the Level of Reflective Teaching Practices among Science Teachers. International Journal of Instruction, 13(1), 695-712. https://doi.org/10.29333/iji.2020.13145a 


\section{INTRODUCTION}

Research on reflective teaching and learning practices goes back to many years (Dewey, 1933; Schön, 1983; Ross, 1989). As its name suggests, reflective practice is a deliberate act of critical thinking and contemplation about learning and teaching to draw on insightful penetrations and improve further experiences. Despite the existence of numerous theoretical studies related to reflective teaching practices, there is a paucity of empirical research on gauging teachers' employment of reflective teaching practices and on the relevance of teacher critical reflection to student achievement. To fill the gap, the present study strives to explore this issue and to inquire into the relationship between these two variables.

Many studies point that teachers' use of reflective teaching practice lies at the low or medium level. As an instance, despite all the local and international efforts to improve the teaching/learning profession in Jordanian schools, the results of the National Assessment of Knowledge Economy Skills indicated that students achieved a low level or a very low level in thinking skills (Ababneh, Tweissi and Abu Lebda, 2015). Similarly, the findings of the International Study of Mathematics and Science (TIMSS, 2015) confirmed that education in Jordanian schools helps students to memorize and remember information, but neglects problem-solving skills and critical thinking development (Abu Lebda, Al-Twaissi, and Ababneh, 2017). In the same perspective, The Program for International Student Assessment (PISA) that measures students' reading, mathematics, and science recommended the necessity of reviewing teaching methods to propel higher thinking skills and collaborative problem solving (Ababneh, Al-Twaissi, and Abu Lebda, 2017). Henceforth, principals must control this fearful conundrum to promote students' levels and to meet the requirements of the modern competitive world.

In another milieu, Hassan \& Mojtaba (2018) investigated Iranian EFL teachers' perception of their own reflective teaching and found that their reflective teaching lies at a medium level due to the 'lack of knowledge', 'affective-emotional' and 'teaching situation' inhibitors. In the same perception, Naicker \& Rensburg (2018) demonstrated that teachers recognize the importance of reflective practice, but do not essentially make efforts to develop their own reflective practices. They pointed out in their abstract "unless educators are trained to practice reflection and to facilitate activities that promote the development of reflective learners, the role of the educator in promoting reflective learning by students will be limited."

Moreover, several studies reveal that many teachers need adequate training in reflective teaching practices to increase student achievement. Indeed, reflective practice becomes a crucial component of the teaching curriculum in many parts of the world. Ashraf \& Zolfaghari (2018) linked teachers' practical teaching with learners' achievement and proved that "reflective teachers are involved in analyzing, discussing, evaluating, changing, and developing their practice, which will eventuate into student improvement" (p. 432). On her part, Baporikar (2016: 14) strongly asserted, "Undoubtedly reflection is core to learning. With today's twenty-first century learners, it is important that educators advocate integrating twenty-first century skills into their reflection activities". 
In the same line, Saperstein, Lilje, \& Seibert (2015: 142) affirmed, "Although reflective practice is often not intuitive [...] it is a skill that can be cultivated through development and implementation of a reflective practice curriculum." Likewise, Pang (2017: 174) emphasized, "the topic of reflective practice ... is key to the professional development of teachers in 21st century classrooms." Eventually, Legare \& Armstrong (2017: 312) believed that "Reflective practice contributes to lifelong learning and professional development. In his interview with Farrell, Pang (2017: 177) upheld that "Some writers have advocated that reflective practice should be taught explicitly to student teachers." In response to him, Farrell declared, "Yes, I agree as it is a skill that can be learned [yet] we must be cautious against hasty referencing to Dewey, Schon or Farrell to legitimize an approach without a full understanding of the approach". Overall, teachers need an adequate training in reflective practice to promote their learners' reflective practice and achievement as a lack of a comprehensive account of this approach may lead to disastrous results.

\section{Statement of the Problem}

The Jordanian Ministry of Education has implemented great educational reforms and launched innovative teacher professional development programs, yet the teaching of sciences in schools is still carried out through traditional direct lecturing that improves neither reflective thinking nor scientific knowledge. The problem seems to reside in teachers who have a low level in reflective teaching practice, and this subsequently leads to a generation of poor reflective learners with low achievement levels.

\section{Aim of the Study}

The aim of this study is to uncover the degree of reflective teaching practice employed by science teachers in Jordan in terms of gender, experience, qualification, and teaching load. The assumption is that the falling standards of students may be due to the lack of using reflective teaching practices.

\section{Research questions}

The study attempts to answer the following questions:

1. To what extent do Jordanian science teachers employ reflective teaching practice in the classrooms?

2. Does the degree of reflective teaching practice amongst science teachers in the classrooms differ according to gender, experience, qualification, and load?

\section{Importance of Study}

The importance of this study lies in its attempt to shed light on the level of employment of reflective teaching practices by Jordanian science teachers. It stresses the value of activating these practices for improving teachers' skills and enhancing students' understanding, thinking skills and favorable attitudes towards learning. Eventually, the study provides some recommendations for promoting teacher professional development through reflective teaching practices at pre-service, in-service and post-service stages.

\section{REVIEW OF LITERATURE}

This study divides the literature review into two sections. The first section highlights theoretical issues concerning reflective teaching practice in order to illuminate the 
fundamental issues necessary for the comprehension of the topic. The second section reports some related empirical studies that would be essential for comparing and contrasting the various results and drawing up valid conclusions.

Reflective teaching practice unravels the processes through which teachers review their past teaching practice, examine their real classroom practice, and suggest better practice for further development. Teachers are supposed to think about every teaching activity in the classroom. They should review, describe, analyze and evaluate the situation in order to get fresh reflective ideas for improving future practices. Reflecting about teaching is not a mere thinking about what and how we teach, but it is a cyclical critical strategy for assessing the actual efficiency of teaching and an ultimate means for heightening teaching professional development.

Historically, the concept of reflection can be traced back to a century ago at the hands of the pioneering scholar John Dewey in the early twentieth century. However, the term has come into the education spotlight in the late 1970's and the commencement of the 1980 's. Then, reflective teaching practice has been gaining momentum since the 1990's amongst researchers and educators. From this time forth, the term has come into common- parlance as an efficient approach in schools and colleges in the twenty-first century. Richardson (1990) showed that reflective practice is not a new concept, but its origin goes back to Dewey who explored it in 1909 and appealed individuals to reflect upon their professional actions and ultimate outcomes.

In fact, for a deep understanding of the state of the art of reflected teaching and learning, one cannot escape the great works of John Dewey. Johnston (2007) reviewed John Dewey and the Art of Teaching: Toward Reflective and Imaginative Practice written by six researchers: Douglas, Simpson, Michael. Jackson, Judy, Aycock (2005). He concluded that these authors investigated Dewey's writings and developed his 'statements into metaphors for teaching'. More specifically as Johnston (2007: 69) stated,

These metaphors include the teacher as artist, lover, wise mother, navigator, gardener, educational pioneer, servant, social engineer, composer, wise physician, builder, leader, and finally (to bring it all back) classroom teacher. Each of these metaphors is found in one or another of Dewey's writings; the authors work through these statements of Dewey's, and form from them a picture of the reflective teacher.

The 1980's witnessed great concerns about inquiring comparison methods whereby researchers embarked on comparing and contrasting the impact of using two different methods on students' performance and achievement. The results indicate that no method that is better than all the other ones at different levels. The focus of theoretical and empirical studies was laid on the search of an effective methodology that not only suits learners but also improves their levels as well. In the 1990's, research sought to uncover teachers' practices in their profession. Therefore, there was a shift from external to internal factors. In line with this, Richards and Lockhart (1996) see that the "reflective approach" represents a shift from "methods" and "external" or "top down" views of 
teaching toward an "internal" or "bottom up" teaching approach that investigates teachers' practices and comes up with appropriate educational proposals.

According to Richert (1990), reflective practice is encapsulated in the aptitude of thinking about what one does and why; i.e., assessing past actions, current situations, and intended outcomes. It favors intelligent reflective practice and discards routine actions. In the same vein, Rayford (2010) sees that reflective teaching is a procedure that enables the teacher to see himself in the mirror in order to bring about the necessary changes for improving teaching. Mathew, Mathew and Peechattu (2017: 127) state that reflective teaching is not just "thinking about one's teaching", but it is "a process where teachers think over their teaching practices, analyze how something was taught and how the practice might be improved or changed for better learning outcomes." They also added that

A person who reflects throughout his or her practice is not just looking back on past actions and events, but is taking a conscious look at emotions, experiences, actions, and responses, and using that information to add to his or her existing knowledge base and reach a higher level of understanding (p. 127).

Reflecting about all daily actions is necessary, but it is not always easy to get rid of the habits and beliefs that are unconsciously grounded in us. The hidden slogan that most teachers usually hold is 'I teach as I was taught by a teacher who taught me as he had been taught'. Indeed, many teachers keep dispensing the same lessons using the same method for many years. Whatever the causes of sticking to these flawed repetitive actions, they result in their solidification and long-life preservation. In short, when fossilization reigns, mediocrity sways and looms large.

Brookfield (1995) examines teacher assumptions and comes up with a three-fold distinction: paradigmatic, prescriptive, and causal assumptions. He considers paradigmatic assumptions as the most difficult ones to discover and change because they form the structuring ideas that dissect the world into main categories. He regards prescriptive assumptions as beliefs about what should happen in any situation such as how teachers or students should behave. He views causal assumptions as predictive ideas about how different events occur under certain conditions and how we can change them. An example of this is that if a teacher makes a mistake in the classroom, this creates a relaxed atmosphere for students to talk without inhibition. These assumptions are the easiest ones to uncover.

Many teachers take for granted their teaching habits that are generally wrapped in erroneous assumptions. To date, questioning these practices seems to be of paramount importance for teacher academic development. Richards and Lockhart (1996) show that teacher' attitudes, ideas and beliefs about teaching have an influence on their classroom practices and stress the need to unravel the thinking processes underlying them.

Importantly enough, Brookfield (1998) views teachers as prisoners who are trapped within their own assumptions about viewing their experiences. He shows that reflective practice is an inquiry whereby teachers examine the assumptions that frame their teaching through four lenses: the lens of their own autobiographies as learners of 
reflective practice, the lens of learners' eyes, the lens of colleagues' perceptions, and the lens of theoretical, philosophical, and research literature. Eventually, reviewing classroom practices through these lenses enables teachers to question their assumptions and diagnose their lacuna.

In the same direction, Pacheco (2011: 1) stresses the need to reflect on teachers' actions in teaching classrooms to bridge the gap between theory and practice. He proposes a model for improving teaching through reflective practice and action research. In the same line, Zalipour (2015: 4) underlies that

Reflective practice challenges teachers who have unquestioned assumptions about good teaching and encourages them to examine themselves and their practices in the interest of continuous improvement.

Above all else, teachers' assumptions must be examined in rigorous methodological manners. In this perspective, some attempts strive at establishing a new method based on the maximum use of reflection by teachers. Olaya (2018) investigates whether reflective teaching can become a strategy for teaching professional development and concludes that it is "an alternative to raise awareness about science teaching, and as a means to encourage teachers to open their minds, update their teaching methodologies, and make adjustments to their lessons" (p. 149).

In harmony with this view, some researchers (Richards and Lockhart, 1996; Pacheco, 2011; Olaya, 2018) suggest the employment of a range of effective instruments and strategies to record reflective classroom experiences. The most commonly used strategies include journals, diaries, notebooks, peer observation, portfolios, reports, surveys, questionnaires, interviews, self-monitoring methods, case analysis, action research as well as audio and videotape recordings or a combination of some these forms. The use of reflective teaching strategies represents a challenging task that necessitates not only passion and commitment on the part of teachers but also more time, effort and sacrifice as well for dispensing good teaching quality.

Reflective teaching practice seeks to unravel the hidden introspections of teachers about their teaching practices and to shape them in an approach that investigates them in a rigid scientific way. It converts the tacit assumptions into explicit statements and provide methodical judgments about their validity. Indeed, while recording what they think and perform not only inside the classroom but also before and after teaching, teachers develop their self-awareness, know their strengths and weaknesses, and plan their professional development in light of modern research literature on the issue. As Mathew, Mathew and Peechattu (2017: 126) stress, "When student teachers carry out systematic enquiry into themselves, they understand themselves, their practices and their students. By constantly looking into their own actions and experiences, they professionally grow in their own."

In addition to the proliferation of numerous studies that examined the theoretical foundations of reflective teaching practice, a battery of experimental research works was carried out to explore how this approach can enhance reflective thinking among teachers and students alike. They investigated the efficiency of this approach in terms of various 
variables such as gender, experience, education, and load, level of reflection, and classroom management.

Tajik and Pakzad (2016) planned and experimented a reflective teacher education course. The analysis of the stimulated recall interviews and journals showed improvements in teachers' reflective teaching as a result of attending the reflective course. In a similar line, Töman (2017) investigated the impact of the reflective teaching practice on the development of teaching skills of the pre-service teachers at Beirut University Faculty of Education Department of Elementary Science Education. Results showed positive effects on promoting reflective thinking skills in planning, implementation and evaluation of a lesson.

Some studies dealt with external factors influencing reflective practice. Al-Qatraoui (2010) study found that using analogical strategies developed students' scientific processes, reflective thinking, action recognition, prediction, deduction and classification processes. In another direction, Al-Atrash (2016) sought to identify the efficiency of a proposed program based on multiple intelligences for developing reflective thinking and mathematical communication skills of the ninth-grade pupils in Gaza. He expressed an urgent need to employ programs that are based on multiple intelligences, reflective thinking and mathematical communication skills to promote students' standards.

Other studies tackled the relationship between reflective practice and gender among students. Almorshid (2014) investigated the levels of reflective thinking among Al-Jouf University students in terms of gender and detected a correlation between the acquired level of reflective thinking and students' grade point average. A survey was designed based on Kember's RTQ (Kember et al., 2000) which comprises four levels: Habitual Action, Understanding, Reflection, and Critical Reflection. The study revealed that the overall level of reflective thinking among Al-Jouf University students has not reached the minimum level of $75 \%$. The findings also showed a decline at all levels of reflective thinking amongst students in first, second and third years, but there is a growth in the fourth year. The study also revealed the presence of significant differences between males and females at all levels of reflective thinking in favour of males except for the Habitual Action level.

In the same perspective, Al-Sa'ydeh (2016) investigated reflective thinking and its relationship with the demographic variables of gender and grade among gifted students in King Abdullah II schools for excellence in Jordan. The results showed that the level of reflective thinking was average and there were statistically significant differences to the gender variable in favor of males and due to the grade variable in favor of secondary school students. The researcher recommended the urgent need of training students to learn reflective thinking strategies.

Alongside with the previous studies, some research works sought to gauge the level of reflective teaching practice among teachers. Ostaz (2011) study aimed at discerning the extent of using reflective thinking among science teachers at the basic stage in UNRWA and Governmental schools. The results showed that the level of reflective thinking was 
less than $70 \%$ and that there were no significant differences attributed to gender, scientific qualifications and educational institution. Yet, there were significant differences attributed to educational experience in favor of long experience. Similarly, Hasan (2013) strived at identifying the effectiveness of a reflective teaching-based program on developing teacher pre-service skills in Egypt and Saudi Arabia. The results revealed a low level of using reflective teaching practice in both countries. According to them, the new program was effective in developing reflective teaching skills in accordance with experiential, constructive theory.

It is noteworthy that some researchers found that reflective teaching practice might result in effective classroom-management. Al-Jabber (2013) investigated the effectiveness of reflective teaching tools in solving classroom management problems for science student teachers at Teachers' College in King Saud University. The results showed positive impacts of the use of reflective teaching tools on students' acquisition and behaviour. The use of reflective practices in teaching helps students regulate their time management in the classroom and minimize ineffective conversation management, excessive daydreaming, inappropriate dialogues, disobedience to teacher's instructions, and hyperactive movements.

In light of the results of the all these studies, the present article seeks to explore reflective teaching practice in terms of four demographic variables: gender, qualification, experience, and load. We opted for conducting these four variables not only because they are not deeply investigated but also because they are significant for further research development.

\section{METHOD}

\section{Population}

The population of this study comprised all male and female science teachers enrolled at Bani Kenanah educational directorate from Irbid Governorate in the 2017-2018 academic year. The population of this study was representative and homogenous of almost all the existing social government teachers in Jordan in terms of gender, age, nationality, education, culture native language, and exposure to English as a foreign language.

\section{Sample}

A sample of 256 Jordanian teachers from Bani Kenanah education directorate participated in this study. All of them held a major in either physics, chemistry, or biology. While some of them held a Diploma in education or ICT, others held a Master of Arts degree in their specialization or in science education. Some of them had a teaching experience in the Jordanian Ministry of Education and others in the Gulf countries. All of them had the opportunity to teach heterogeneous classes. The teachers were randomly selected without any discriminating factor (Gay \& Airasian, 2003). In the beginning, the present researchers identified all the schools that incorporate male and female science teachers teaching physics, chemistry, and biology courses at the Directorate of Education in Beni Kenana, Northern Jordan. The schools' names were then written on small paper clips, closed, and placed in separate boxes according to the 
sex of the school because male schools are segregated from female schools in Jordan. The schools were then randomly chosen to retrieve paper scraps containing school names, and then the questionnaires were sent to all science teachers (physics, chemistry, biology) in the schools that formed the study sample according to the previous step. Teachers were contacted by phone three days after the questionnaire was sent to remind them and incite them to mobilize. A week later, more than $80 \%$ of the distributed questionnaires were collected. After that, the raw data was entered into SPSS software, processed and refined, and then the appropriate statistical analysis was conducted to answer the study questions.

Table 1 shows the participants' distribution according to their gender, experience, qualification, and load.

Table 1

Participants' Distribution by Gender, Experience, Qualification and Load

\begin{tabular}{clll}
\hline Variable & & $\mathrm{N}$ & $\%$ \\
\hline \multirow{2}{*}{ Gender } & Male & 84 & $33 \%$ \\
& Female & 172 & $67 \%$ \\
\cline { 2 - 4 } Experience & $1-5$ & 40 & $16 \%$ \\
(Year) & $6-10$ & 61 & $24 \%$ \\
& $11-15$ & 62 & $24 \%$ \\
& More than 15 & 93 & $36 \%$ \\
\cline { 2 - 4 } Qualification & Bachelor & 147 & $57 \%$ \\
& Bachelor + High diploma & 46 & $18 \%$ \\
& Master & 50 & $20 \%$ \\
LhD & 13 & $5 \%$ \\
Load & Less than 10 & 29 & $12 \%$ \\
(Class/Week) & $11-20$ & 144 & $56 \%$ \\
& More than 20 & 83 & $32 \%$ \\
\hline
\end{tabular}

Table 1 shows participants' distribution by gender, experience, qualification, and load. The sample included 256 science teachers: 84 males and 172 females. They were distributed as follows: $36 \%$ of the teachers with an experience more than 15 years, $24 \%$ with an experience ranging from 6-10 and 11-15 years, and 16\% new teachers with less than five years of experience. Teachers' educational levels run as follows: Level one (Bachelor of Arts) included 147 teachers out of 256 with 57\% representing the highest percentage. Level two (Bachelor + High diploma) included 18\%. Level three (Master of Arts) included $20 \%$, and level four (Ph. D.) with 5\% only denoting the lowest level. Finally, teachers' load was divided into three groups based on the number of classes covered per week. The lowest group had a load less than 10 classes a week with $12 \%$, the highest percentage had a load of 11-20 classes a week, whereas $32 \%$ of them had more than 20 classes a week.

\section{Study Design}

To investigate the objectives of the study, the researchers followed the descriptive analytical method.

\section{Study variables}

Independent variables: 
1. Teachers' gender (Male, Female)

2. Teachers' experience per year: $(1-5,6-10,11-15$, more than 15$)$

3. Teachers' qualification: (Bachelor, Bachelor with high diploma, Master, Ph. D.)

4. Teachers' load: number of classes a week: (less than 10, 11-20, more than 20)

Dependent variables:

1. The degree of employing reflective teaching practices in the classrooms by science teachers.

2. The impact of reflective teaching practice on developing teachers' and students' reflection.

\section{Research Instrumentation}

The researchers reviewed the theoretical literature related to reflective teaching that focused on enhancing students' understanding, achievement, attitude, and motivation toward learning. The researchers adopted the research instrument from Ryan (2014) and elaborated it according to Likert scale with five levels (Very often: 5, Often: 4, Neutral: 3, Rarely: 2, and Very rarely: 1). The instrument aimed at measuring the level of reflective teaching in the classrooms among science teachers.

Validation of the instrument

To check the validity of the study instrument, the initial version was presented to eight experts in teaching and learning. Three of them held a Ph. D degree in curriculum and instruction, and they taught at the university level. Two held a master's degree in science education and worked as educational supervisors at Bani Kenanah education directorate. Two-science teachers: one of them holding a master's in chemistry and the other a bachelor's in physics and a high diploma in teaching science. The Instrument included 32 items. The experts were invited to give their opinions regarding the appropriateness of individual items in terms of language wording, and suitability for measuring goals designed to measure. In light of their feedback and comments, necessary adjustments were made, five items were deleted based on the experts' recommendations, and the wordings of several items were amended. Overall, the final version included 27 items.

\section{Reliability of the instrument}

To ensure the reliability of the instrument, the present researchers applied the instrument only one time for 35 science teachers from the second Irbed education directorate. Then, they calculated the coefficient (Cronbach) Alpha, and the reliability coefficient was 0.76 . This value was considered acceptable in the social sciences (Obiedat et al., 2016; Al-Kellani; and Al-Shraifeen, 2011).

\section{Statistical Standard}

The following equation was adopted for the purpose of paragraph classification (AlRashidi, 2018).

$$
\begin{aligned}
& =(\text { Upper limit of scale }- \text { minimum scale }) / \text { number of required categories } \\
& =(5-1) / 3 \\
& =1.33
\end{aligned}
$$


The categories are (1 - 2.33: Weak (W), 2.34 - 3.60: Medium (M), and 3.60 - 5: Strong (S)).

\section{Research Procedures}

For conducting this study, we asked for a recommendation letter from the Jordanian Ministry of Education. As soon as we received the approval letter, we embarked on piloting the research work.

The next step was selecting the sample from the population and appointing participants to collect the data. Then, we proceeded with the random selection of the teachers in coordination with Bani Kenanah Provincial Directorate of Education. In the beginning of April 2018, we started collecting the data from the teachers, and this process lasted until the end of May 2018. Eventually, the SPSS program was used to analyze the data, and valid statistical analyses were provided.

\section{FINDINGS}

To answer the first question of the study: "To what extent do science teachers employ reflective teaching practices in the classrooms?" the researchers analyse the data in terms of Mean score and standard deviation of the instrument items, and the results were cast in Table 2.

Table 2

Means and SD of Reflective Teaching Practices among Jordanian science teachers (N=256; Weak: W; Medium: M; And Strong: S)

\begin{tabular}{|c|c|c|c|c|}
\hline NO & Items & Mean & SD & Degree \\
\hline 1 & I already envisage the teaching procedures I must do during my teaching. & 1.69 & .52 & W \\
\hline 2 & I seek to hire my new acquaintances in my teaching. & 1.53 & .68 & W \\
\hline 3 & I keep records of my annual work (plans, means ... etc.). & 1.80 & 1.01 & $\mathrm{~W}$ \\
\hline 4 & I think a lot about what I teach students. & 1.62 & .72 & W \\
\hline 5 & I make sure to prepare school plans constantly. & 1.87 & .94 & W \\
\hline 6 & I accept feedback from the supervisor or manager. & 1.84 & .91 & W \\
\hline 7 & While teaching, I make sure to compare the current lecture with the previous one. & 1.94 & .94 & W \\
\hline 8 & I avoid making judgments about students' works before reviewing and analyzing them. & 1.88 & .71 & W \\
\hline 9 & I think deeply about my teaching practices that I feel they are inappropriate. & 1.92 & .83 & $\mathrm{~W}$ \\
\hline 10 & I make sure to modify my teaching plans constantly. & 2.18 & 1.04 & $\mathrm{~W}$ \\
\hline 11 & I encourage students to reflect on all what they do during the lesson. & 1.95 & 90 & $\mathrm{~W}$ \\
\hline 12 & $\begin{array}{l}\text { 1 allow others (teachers, students, managers, and supervisors) to evaluate } \mathrm{n} \\
\text { performance. }\end{array}$ & 2.17 & 1.14 & W \\
\hline 13 & I offer students opportunities to provide me with feedback during my teaching. & 2.07 & .96 & $\mathrm{~W}$ \\
\hline 14 & I discuss my teaching practices with my colleagues. & 2.31 & 1.12 & $\mathrm{~W}$ \\
\hline 15 & I identify the basic themes that I read, watch, and hear. & 2.09 & .95 & $\mathrm{~W}$ \\
\hline 16 & I allow my colleagues to observe me while teaching in class. & 2.16 & 1.07 & W \\
\hline 17 & I read research works and articles on teaching practices. & 2.62 & 1.23 & M \\
\hline 18 & During class, I consider the following procedure before implementing it. & 1.95 & .80 & W \\
\hline 19 & I identify similar actions in my various teaching practices. & 2.20 & .94 & $\mathrm{~W}$ \\
\hline 20 & I take notes of others' successful experiences in my teaching. & 2.55 & 1.23 & M \\
\hline 21 & I am very keen to observe classroom classes performed by my colleagues. & 2.75 & 1.25 & M \\
\hline 22 & I record what I felt inappropriate in a special file to avoid doing it in the future. & 3.01 & 1.27 & M \\
\hline 23 & I feel the need to change constantly my teaching practices. & 2.38 & 1.09 & M \\
\hline 24 & I participate in the school teaching teams. & 2.56 & 1.23 & M \\
\hline 25 & I conduct procedural research on teaching. & 3.58 & 1.15 & M \\
\hline 26 & $\begin{array}{l}\text { I contribute in the preparation of articles and researches for publication in scientifi } \\
\text { journals or websites. }\end{array}$ & 3.97 & 1.15 & S \\
\hline 27 & $\begin{array}{l}\text { I use audio and video recordings of my classes for subsequent observation. } \\
\text { Overall }\end{array}$ & $\begin{array}{l}3.31 \\
2.29\end{array}$ & 1.46 & $\begin{array}{l}\mathrm{M} \\
\mathrm{w}\end{array}$ \\
\hline
\end{tabular}


The results in Table 2 show that the total mean score for science teachers is 2.29 . This shows that their level of employing reflective teaching practices in the classrooms is utterly weak. The highest Mean score for science teachers is 3.97 (Strong) corresponding to item 26 , which indicates that science teachers are very active in writing and publishing educational research works because the ministry of education decreed research publication as one of the requirements for ranking teachers. This is followed directly by item 25 with a Mean score of 3.58 (Medium) which supports the previous one that science teachers are seriously doing action research in teaching and learning. Then, followed by item 27 with a Mean 3.31. This indicates that science teachers record some of their classes to recall and reflect on their behaviors and practices in the classes for improving their skills and competencies.

However, the second item scored the lowest with a Mean of 1.53 (Weak). This item addresses that science teachers are not trying to employ their new knowledge in their teaching. It shows that they are not learning and reflecting, or they are not motivated to practice new skills in their classes. Indeed, their attitude towards their job is not positive enough to enable them to try out new ideas in teaching for enhancing students' learning. This is supported by the next lowest item which is number 4 with a Mean 1.62 (Weak) and demonstrates that the teachers do not think a lot about what they teach their students.

To answer the second question: "Does the degree of reflective teaching practices employed by science teachers in the classrooms differ according to gender, experience, qualification, and load?", the researchers analyzed the statistical Means and standard deviation differences as shown in Table 3:

Table 3

Means and Standard Deviations of Teachers' Reflective Teaching Practices in the Classrooms in Terms of Gender, Experience, Qualification, and Load

\begin{tabular}{lllll}
\hline \multirow{3}{*}{ Gender } & Variable & $\mathrm{N}$ & Mean & SD \\
& $\mathrm{M}$ & 84 & 2.42 & 0.53 \\
& $\mathrm{~F}$ & 172 & 2.24 & 0.49 \\
& Total & 256 & 2.30 & 0.51 \\
\cline { 2 - 5 } Experience & $1-5$ & 40 & 2.20 & .480 \\
(Years) & $6-10$ & 61 & 2.30 & .530 \\
& $11-15$ & 62 & 2.37 & 0.48 \\
& More than 15 & 93 & 2.29 & .520 \\
& Total & 256 & 2.30 & 0.51 \\
\cline { 2 - 5 } Qualification & Bachelor & 147 & 2.29 & 0.52 \\
& Bachelor + High diploma & 46 & 2.25 & 0.46 \\
& Master & 50 & 2.38 & 0.51 \\
Load & PhD & 13 & 2.21 & 0.53 \\
Class/week & Total & 256 & 2.29 & 0.51 \\
\cline { 2 - 5 } & Less than 10 & 29 & 2.38 & 0.52 \\
& $11-20$ & 144 & 2.33 & 0.47 \\
\hline
\end{tabular}


The results in table 3 show that there is a difference in the Mean score between males and females with 0.18 for males and 2.42 for females with the standard deviation of 0.53 and 0.49 . Regarding teachers' experience, Table 3 indicates that the category of teachers with teaching experience (11-15 years) is the highest towards reflective practices in the classrooms with a Mean of 2.37 and a standard deviation of 0.48 . Yet, the reflective practices in the classrooms of (1-5 years) category are the lowest with a Mean of 2.20 and a standard deviation of 0.48 . According to teachers' qualification, the results show that the Master holders' mean is the highest with a mean of 2.38 with a standard deviation of 0.51 , whereas the lowest mean is 2.21 for the Ph. D. holders with a standard deviation of 0.53. Finally, the results indicate that teachers who are assigned the highest load record the lowest mean with 2.21 and a standard deviation of 0.56 while teachers who are assigned the lowest load record the highest mean: 2.38 with a standard deviation of 0.52 .

The examination of the above results reveals apparent differences in the calculation mean of the degree of employing reflective teaching practices in the classrooms by science teachers according to the variables of gender, experience, qualification, and load. To ascertain the validity of the differences, the researchers performed the ANOVA analysis, and the results are presented in Table 4 as follows:

Table 4

ANOVA Test of Science Teachers' Reflective Teaching Practices in the Classrooms

\begin{tabular}{lllllll}
\hline \multirow{2}{*}{ Source } & & $\begin{array}{l}\text { Type III Sum } \\
\text { of Squares }\end{array}$ & df & Mean Square & F & Sig. \\
\hline \multirow{2}{*}{ Intercept } & Hypothesis & 1222.950 & 1 & 1222.950 & 702.097 & .024 \\
& Error & 1.742 & 1 & $1.742^{\mathrm{a}}$ & & \\
Gender & Hypothesis & 1.742 & 1 & 1.742 & 6.912 & .009 \\
& Error & 64.010 & 254 & $.252^{\mathrm{b}}$ & & \\
Intercept & Hypothesis & 1228.755 & 1 & 1228.755 & 5524.357 & .000 \\
& Error & .765 & 3.442 & $.222^{\mathrm{a}}$ & & \\
Experience & Hypothesis & .661 & 3 & .220 & .853 & .466 \\
& Error & 65.091 & 252 & $.258^{\mathrm{b}}$ & & \\
Intercept & Hypothesis & 664.550 & 1 & 664.550 & 3156.382 & .000 \\
& Error & 2.149 & 10.208 & $.211^{\mathrm{a}}$ & & \\
Qualification & Hypothesis & .545 & 3 & .182 & .702 & .552 \\
& Error & 65.206 & 252 & $.259^{\mathrm{b}}$ & & \\
Intercept & Hypothesis & 895.019 & 1 & 895.019 & 2115.858 & .000 \\
& Error & 1.134 & 2.681 & $.423^{\mathrm{a}}$ & & \\
Load & Hypothesis & .943 & 2 & .471 & 1.841 & .161 \\
\hline
\end{tabular}

Table 4 shows that there are statistically significant differences in science teachers' reflective teaching practices in the classrooms due to only one independent variable which is teachers' gender where $F=6.912$ and $\alpha<0.05$. On the other hand, the results indicate that there are no statistically significant differences in science teachers' reflective teaching practices in the classrooms due to the other study variables (experience, qualification, and load). Regarding teachers' experience, table 4 shows that there are no statistically significant differences where $F=0.853$ and $\alpha=0.466$. The results also indicate that there are no statistically significant differences in science 
teachers' reflective teaching practices in the classrooms due to teachers' level of qualification: $\mathrm{F}=0.702$ and $\alpha=0.552$. Finally, the results show that there are no statistically significant differences in science teachers' reflective teaching practices in the classrooms for the teachers' load variable; the significance of the teachers' load is 0.161 , and $\mathrm{F}=1.841$.

\section{DISCUSSION}

Concerning the question: "Why is the level of the use of reflective teaching practice low among science teachers?" Several researchers (Ostaz, 2011; Hasan, 2013; Almorshid, 2014; Al-Sa'ydeh, 2016; BuQhoos, 2017) suggest that there are several justifications that may explain this finding. First, the scientific content of science courses is not designed in a way that is consistent with the methodology of reflective teaching practice, and this, of course, does not encourage science teachers to adopt this strategy. Second, science teachers do not perform reflective practice in their daily educational behavior. Besides, there is a lack of opportunities for direct interaction and dialogue among science teachers to develop their skills in reflective teaching practice. Most importantly, the results pinpoint that teachers' difficulties in possessing reflective teaching skills and practice are due to the lack of pre- and in-service training that should be provided by specialists in the field. In sum, all these impediments represent a real obstacle that teachers should overcome in order to improve their educational reflection.

According to the results, there is no difference in terms of scientific qualification, experience and teaching load of science teachers. Several researchers (Ostaz, 2011; AlSa'ydeh, 2016; Abu-Sultan and Abu-Asker, 2017; Al-Rfou'a, 2017; BuQhoos, 2017) believe that the lack of reflective teaching practices of science teachers is due to other reasons that are not related to the scientific qualification. In fact, reflective teaching practice is a new direction in the preparation of teachers, and teachers regardless of their scientific qualifications are not trained in this field. The science teachers who work in the public sector provide the same content under the same method and work under the same conditions. Another discouraging problem for teachers is that all of them earn the same salary irrespective of their experience, qualification and educational standard. This, of course, reduces the motivation of science teachers to devote themselves to teaching and experimenting with modern strategies and techniques. On the other hand, science teachers are subject to the same professional development programs both before and during the service regardless of the academic qualification. They are available to all and are offered free of charge by the Ministry of Education. Eventually, all these factors strongly justify the nonexistence of differences among science teachers in terms of scientific qualification, experience and teaching load.

More importantly, the results indicate that there is a statistically significant difference among teachers in terms of gender and in favor of males. In contrast to male teachers who are free of any domestic duties in the Arab societies, female teachers are also considered as housewives who are responsible for carrying out different daily household chores. In this context, Ostaz (2011) suggests that this statistically significant difference in gender in favor of males is due to the nature of the Jordanian society that largely depends on females at home after the end of their school time. When the woman returns 
home, she must carry out household obligations such as preparing food for the family, cleaning, washing, ironing and other works. This burden reduces the time available for the female teacher to reflect on the lessons she has already dispensed to her students and to prepare for the coming lessons in an adequate manner. However, when the male teacher returns home, he does not have many commitments at home, especially if has no other work to increase his family income. Therefore, the male teacher has enough time to reflect on the preparation of his lessons and the accomplishment of his teaching tasks somewhat appropriately. Al-Rfou'a (2017) confirms this viewpoint and further asserts that the Arab society, in general, is male-oriented that often gives males more opportunities for discussing, debating and experimenting new ideas.

Finally, yet importantly, the low level of the use of reflective teaching practice among science teachers can be rendered to severe socio-economic factors that negatively affect the teaching profession. Importantly although not directly related, the lack of time due to the burden of academic and administrative charges put on teachers may be regarded as another extraneous factor that may hamper any form of educational critical thinking and reflection. In addition, the country is experiencing a period of financial hardship; and consequently, teachers suffer from harsh economic and social conditions with no augmentation of their salaries for a long time. Their priority in life is to attempt to fulfill their physical needs and to cover the requirements of life. The high cost of life prompts most teachers to search for new sources of income after the end of school hours; the net effect of this endeavor makes teachers return home tired at the end of the day. The ancillary occupation arguably reduces the chances of adequate preparation and any form of thinking about innovative teaching methods.

\section{CONCLUSION AND RECOMMENDATION}

Finally, yet importantly, in spite of all the educational and social problems that confront Jordanian teachers in their daily life, they have to surmount their hurdles and consider the educational findings of current theoretical and empirical research works. They have to keep abreast of recent developments in the field of teaching and learning. Overall, the reflective teaching approach should, in no way, be estranged from any pedagogical practice if teachers want to accomplish professional development and long-life prosperity in the twenty-first century. The study recommended the necessity of raising teachers' awareness about the importance of using reflective teaching practices. It also pinpointed the need for professional development programs in order to enhance teachers' skills in reflective teaching in the classroom. The study also recommended the obligation to supplement all disciplinary teacher guides with efficient mechanisms for furthering reflective teaching practices in the classroom.

\section{REFERENCES}

Ababneh, E., Al-Twaissi, A., \& Abu Lebda, K. (2017). Program for international student assessment (PISA2015): National report. Amman: National Center for Human Resources Development (NCHRD). 
Abu Lebda, K., Al-Twaissi, A., \& Ababneh, E. (2017). Jordanian national report of TIMSS 2015 study: National report. Amman: National Center for Human Resources Development (NCHRD).

Abu-Sultan, A., \& Abu Asker, M. (2017). The reflective practices of science teachers in the upper basic stage in the northern Gaza. Journal of Palestine University for Research and Studies. 7(1), 1-27.

Al-Atrash, T. O. N. (2016). Effectiveness of a suggested program based on multiple intelligences in developing the skills of reflective thinking and mathematical communication among ninth graders in Gaza (Unpublished master thesis). The Islamic University, Gaza.

Aljabber, J. (2013). The effectiveness of reflective teaching tools in solving classroom management problems for science student teachers at teachers' college in King Saud University. International Journal of Educational Research, 33, 91-128.

Al-Kellani, A., \& Al-Shraifeen, N. (2011). Introduction to research in educational and social sciences. Amman: Dar Almaisarah.

Almorshid, Y. (2014). Levels of reflective thinking among Al-Jouf University students: A cross-sectional study. Taiba University J. of Educational Sciences, 9(2), 163-184.

Al-Qatraoui, A. (2010). The effect of using 'analogical strategy' on developing science process and reflective thinking skills in sciences among eighth graders fundamental school (Unpublished master thesis). Islamic Gaza University, Gaza.

Al-Rashidi, F. (2018). The level of using the reflective practices among secondary school teachers-from their points of view- in Baredah governorate. Journal of Faculty for Basic Education in Educational and Human Sciences, 38, 284-294.

Al-Rfou'a, M. (2017). The degree to which tenth grade students possess reflective thinking skills and its relationship with their academic achievement. Journal of the Faculty of Education, Al-Azhar University, 174(1), 721-752.

Al-Sa'ydeh, N. M. (2016). Reflective thinking and its relationship with some demographic variables among gifted students in King Abdullah ii schools for excellence in Jordan. Studies in Educational Sciences, Jordan, 43(4), 1747-1757.

Angel, G. (2015). PISA 2015 Results in Focus. Andreas Schleicher Andreas. Schleicher@oecd.org. Paper see also [online]. [Accessed 16 March 2019]. Available from the World Wide Web: http://www.oecd.org/pisa/pisa-2015-results-in-focus.pdf.

Ashraf, H., \& Zolfaghari, S. (2018). EFL teachers' assessment literacy and their reflective teaching. International Journal of Instruction, 11(1), 425-436. https://doi.org/10.12973/iji.2018.11129a.

Baporikar, N. (2016). Technology integration and innovation during reflective teaching. International J. of Information and Communication Technology Education, 12(2), 14-22. 
Brookfield, S. D. (1995). Becoming a critically reflective teacher. San Francisco: Jossey-Bass.

Brookfield, S. D. (1998). Critically reflective practice. The Journal of Continuing Education in the Health Professions, 18, 197-205.

BuQhoos, K. (2017). Relationship between reflective thinking and teaching performance of student teachers specialized in science and mathematics. International Journal for Research in Education, 41(1), 38-65.

Gay, L. R., \& Airasian, P. W. (2003). Educational research: Competencies for analysis and application. Prentice Hall.

Griffiths, V. (2000). The reflective dimension in teacher education. International Journal of Educational Research, 33(5), 539-555.

Hassan S. J. M. (2013). A reflective teaching-based program for developing teaching skills in accordance with quality standards and improving the teaching theory of Arabic language and Islamic pre-service teachers in Egypt and Saudi Arabia. International Journal of Education, 2(7), 652-682.

Hassan S. A., \& Mojtaba, F. (2018). Inhibitors to EFL teachers' reflective teaching and EFL learners' reflective thinking and the role of teaching experience and academic degree in reflection perception. Reflective Practice, 19(1), 46-67, doi: 10.1080/14623943.2017.1351353.

Johnston, J. S. (2007). Review of John Dewey and the art of teaching: Toward reflective and imaginative practice by Douglas J. Simpson, Michael P. Jackson, and Judy C. Aycock (2005). Thousand Oaks, CA: Sage Publications. Paideusis, 6(1), 69-71.

Legare, T. L., \& Armstrong, D. K. (2017). Critical reflective teaching practice for novice nurse educators. Teaching and Learning in Nursing, 12, 312-315.

Martin, M. O., Mullis, I. V., Foy, P., \& Hooper, M. (2016). TIMSS 2015 International Results in Science. Publisher: TIMSS \& PIRLS International Study Center, Lynch School of Education, Boston College, Boston College, Chestnut Hill, MA 02467, USA.

Mathew, P., Mathew P., \& Peechattu, P. J. (2017). Reflective practices: A means to teacher development. Asia Pacific Journal of Contemporary Education and Communication Technology, 3(1), 126-131.

Naicker, K., \& Rensburg, G. H. V. (2018). Facilitation of reflective learning in nursing: Reflective teaching practices of educators. Africa Journal of Nursing and Midwifery https://doi.org/10.25159/2520-5293/3386

Obiedat, D. H., Kayed, A., \& Adass, A. (2016). Scientific research: understandable, tools and methods. Amman: Dar Alfiker.

Olaya M. M. L. (2018). Reflective teaching: An approach to enrich the English teaching professional practice. HOW, 25(2), 149-170. https://doi.org/10.19183/how.25.2.386. 
Ostaz, M. (2011). The ability level of reflective thinking of science teachers in basic stage in Gaza. Journal of Al-Azhar University in Gaza, Series of Humanities, 13(1B), 1329-1370.

Pacheco, A. Q. (2011). Reflective teaching and its impact on foreign language teaching. Actualidades Investigativas en Educación, 5(3), 1-19. doi: 10.15517/aie. v5i3.9166.

Pang, A. (2017). Reflective teaching and practice: Interview with Thomas Farrell. RELC Journal, 48(2) $174-179$.

Rayford, C. R. (2010). Reflective practice: The teacher in the mirror (Unpublished master thesis). University of Nevada, Las Vegas.

Richards, J. C., \& Lockhart, C. (1996). Reflective teaching in second language classrooms. Cambridge: CUP.

Richert, A. (1990). Teaching teachers to reflect: A consideration of programme Structure. Journal of Curriculum Studies, 22(6), 509-527.

Richardson, V. (1990). The evolution of reflective teaching and teacher education. In R. T. Clift, W. R. Houston, \& M. C. Pugach (Eds.), Encouraging Reflective Practice: An Examinatinon of Issues and Examplars (pp.3-19). New York: Teachers College.

Ross, D. D. (1989). First steps in developing a reflective approach. Journal of Teacher Education, (March/April), 11-35.

Ryan, A. (2014). The degree of reflective practices of mathematics teachers in Hebron directorates of education \& its relationship with teaching self-efficacy. Manara Journal, 20(1B), 143-173.

Saperstein A. K., Lilje, T., \& Seibert, D. (2015). a model for teaching reflective practice. Military Medicine, 180(4), 142-146.

Schön, D. (1983). The reflective Practitioner. New York: Basic Books.

Schön, D. (1987). Educating the reflective practitioner: Strengthening teachers' reflective decision making. Journal of Staff Development, 9(3), 18-27.

Tajik, L., \& Pakzad, K. (2016). Designing a reflective teacher education course and its contribution to ELT teachers' reflectivity. Australian Journal of Teacher Education, 41(9). http://dx.doi.org/10.14221/ajte.2016v41n9.4.

Töman, U. (2017). Investigation of reflective teaching practice effect on training development skills of the pre-service teachers. Journal of Education and Training Studies, 5(6), 232-239.

Zalipour, A. (2015). Reflective practice: Teaching development unit. Retrieved from https://www.waikato. ac.nz/_data/assets/pdf_file/0006. 